Received: 01.10 .2018

Revised: 27.11 .2018

Accepted: 30.11 .2018

DOI: $10.17804 / 2410-9908.2018 .6 .255-261$

\title{
CONSTRUCTING A MODEL OF THE INTERACTION OF CRACKS IN GAS PIPELINES
}

\author{
V. G. Rybalko ${ }^{\text {a) }}$ D. V. Novgorodov ${ }^{\text {b) }}$, and A. Yu. Surkov ${ }^{\text {c** }}$ \\ M.N. Miheev Institute of Metal Physics, Ural Branch of the Russian Academy of Sciences, \\ 18 S. Kovalevskoy St., Ekaterinburg, 620108, Russian Federation \\ a) (iD https://orcid.org/0000-0003-4045-8967 vgrifm@ mail.ru; \\ b) iD https://orcid.org/0000-0002-5151-8710 ه danil_@inbox.ru; \\ c) (iD https://orcid.org/0000-0002-9281-687X surkov@imp.uran.ru \\ *Corresponding author. E-mail: surkov@imp.uran.ru \\ Address for correspondence: ul. S. Kovalevskoy, 18, Ekaterinburg, 620108, Russian Federation \\ Tel.: +7 (343) 37837 68; fax: +7 (343) 3783768
}

The article presents the results of studying a template with stress corrosion cracking defects. After magnetic particle inspection, a visual analysis of the revealed cracks is carried out in order to fix the traces of mutual influence, which lead to their merging into a common defect with further development. The research has revealed typical ways of crack coalescence, as well as some of their features, and this has allowed us to propose a model for constructing a plausible picture of crack interaction.

Keywords: pipeline, stress corrosion cracking, defect growth, crack coalescence, dipole model.

\section{Acknowledgment}

The work was performed within the state assignment from FASO Russia (the subject of Diagnostics, No. AAAA-A18-118020690196-3)

\section{Reference}

1. STO Gazprom 2-2.3-173-2007. Regulation for complex inspection and diagnosing of trunk gas pipelines subject to stress corrosion cracking. Moscow, Gazprom Expo Publ., 2008, 29 p. (In Russian).

2. Instruktsiya po otsenke defektov trub i soedinitelnykh detaley pri remonte i diagnostirovanii magistralnykh gazoprovodov [Instruction for the Evaluation of Defects in Pipes and Fittings during the Repair and Diagnosis of Main Gas Pipelines]. Moscow, OOO VNIIGAZ Publ., 2013, 117 p. (In Russian).

3. Alimov S.V., Dolgov I.A., Gorchakov V.A., Surkov Yu.P., Surkov A.Yu., Rybalko V.G. Diagnostika korrozionnogo rastreskivaniya gazoprovodov. Atlas [Diagnostics of Gas Pipelines Corrosion Cracking. Atlas]. Ekaterinburg, IMP UB RAS Publ., 2004, 84 p.

4. $\quad$ STO Gazprom 2-2.3-137-2007. Instruction on technologies of welding at construction and repair of field and main gas pipelines. Part 2. Moscow, Gazprom Publ., 2007, 177 p. (In Russian).

5. Broek D. Elementary engineering fracture mechanics. Leyden, Noordhoff International Publishing, 1974, 312 p. 
Подана в журнал: 01.10.2018

УДК 620.179.143.

DOI: $10.17804 / 2410-9908.2018 .6 .255-261$

\title{
ПОСТРОЕНИЕ МОДЕЛИ ВЗАИМОДЕЙСТВИЯ ПРОДОЛЬНЫХ ТРЕЩИН В МАГИСТРАЛЬНЫХ ГАЗОПРОВОДАХ
}

\author{
В. Г. Рыбалко ${ }^{\text {a) }}$, Д. В. Новгородов ${ }^{\text {б) }}$, А. Ю. Сурков ${ }^{\text {в)* }}$ \\ ИФМ УрО РАН, 620108, г. Екатеринбург, ул. С. Ковалевской, 18 \\ a) iD https://orcid.org/0000-0003-4045-8967 ه هrifm@mail.ru; \\ б) (ID https://orcid.org/0000-0002-5151-8710 ه danil_@inbox.ru; \\ в) (iD https://orcid.org/0000-0002-9281-687X ब surkov@imp.uran.ru \\ *Ответственный автор. Электронная почта: surkov@imp.uran.ru \\ Адрес для переписки: ул. Софьи Ковалевской, 18, г. Екатеринбург, 620108, Российская Федерация \\ Тел.: +7 (343) 378-37-68; факс: +7 (343) 378-37-68
}

В статье представлены результаты исследования темплета с трещинами коррозионного растрескивания под напряжением. После магнитопорошковой дефектоскопии проведен визуальный анализ выявленных трещин с целью зафиксировать следы взаимного влияния, которые ведут к их объединению в общий дефект при дальнейшем развитии. Проведенное исследование выявило типичные способы объединения трещин, а также их некоторые особенности, что позволило предложить модель для построения правдоподобной картины взаимодействия трещин.

Ключевые слова: газопровод, коррозионное растрескивание под напряжением, развитие дефекта, объединение трещин, дипольная модель.

\section{1. Введение}

Коррозионное растрескивание под напряжением (КРН) характеризуется большим числом близкорасположенных трещин, которые могут объединяться между собой в процессе роста, что со временем приводит к потере несущей способности стенки трубы и аварийному разрыву магистрального газопровода. Опасность одной трещины можно оценить по ее длине и максимальной глубине, но для построения правдоподобной модели развития и объединения нескольких трещин необходимо провести анализ реального объекта, содержащего дефекты КРН, полученные в результате объединения единичных трещин.

\section{2. Материал и методика}

Предметом исследования служил темплет с трещинами, вырезанный по результатам внутритрубной инспекции из трубы магистрального газопровода диаметром 1420 мм с толщиной стенки 16,5 мм (рис. 1).

На темплете после проведения магнито-порошковой дефектоскопии выявлена область размером 300×100 мм, содержащая наиболее глубокие трещины КРН различной длины. Максимальная глубина трещин составляет около 5,5 мм (рис. 2), это свидетельствует о длительном периоде развития дефектов, что позволяет реализоваться в естественных условиях всем механизмам взаимодействия трещин и дает возможность выявить их при лабораторном исследовании. 


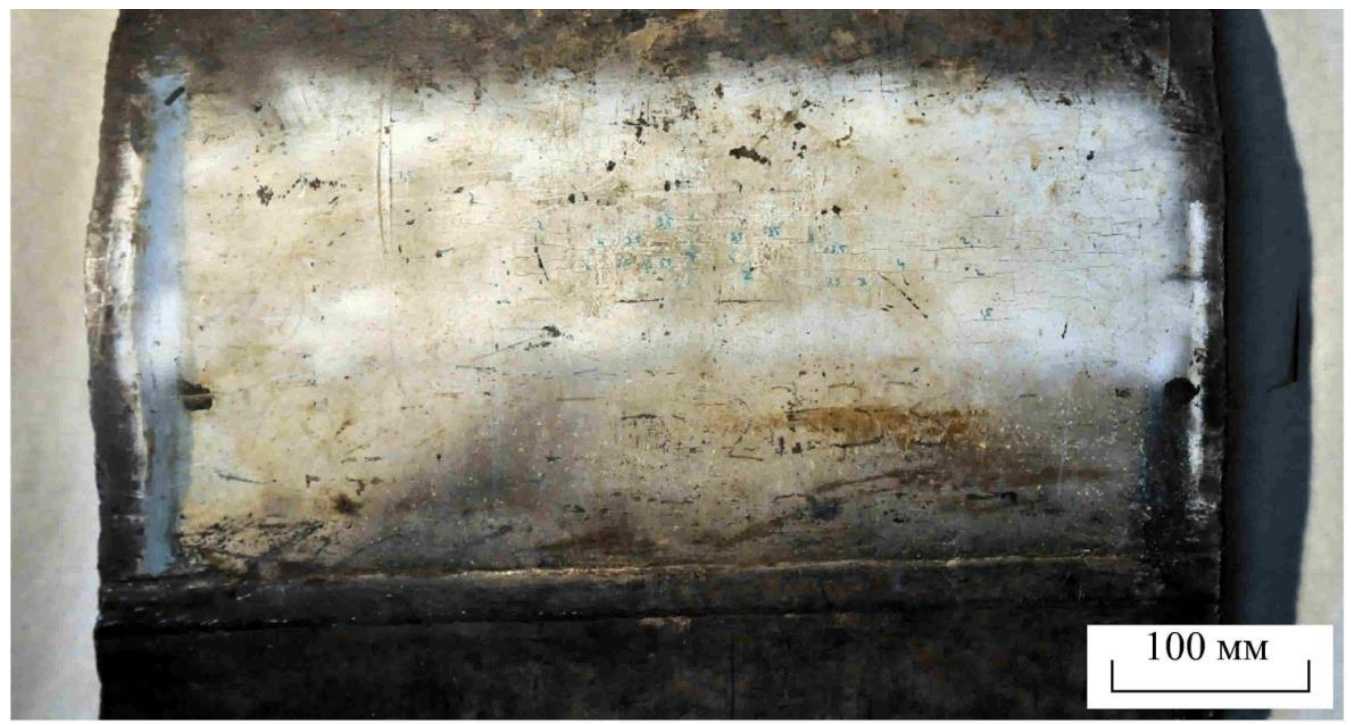

Рис. 1. Темплет с трещинами из трубы магистрального газопровода

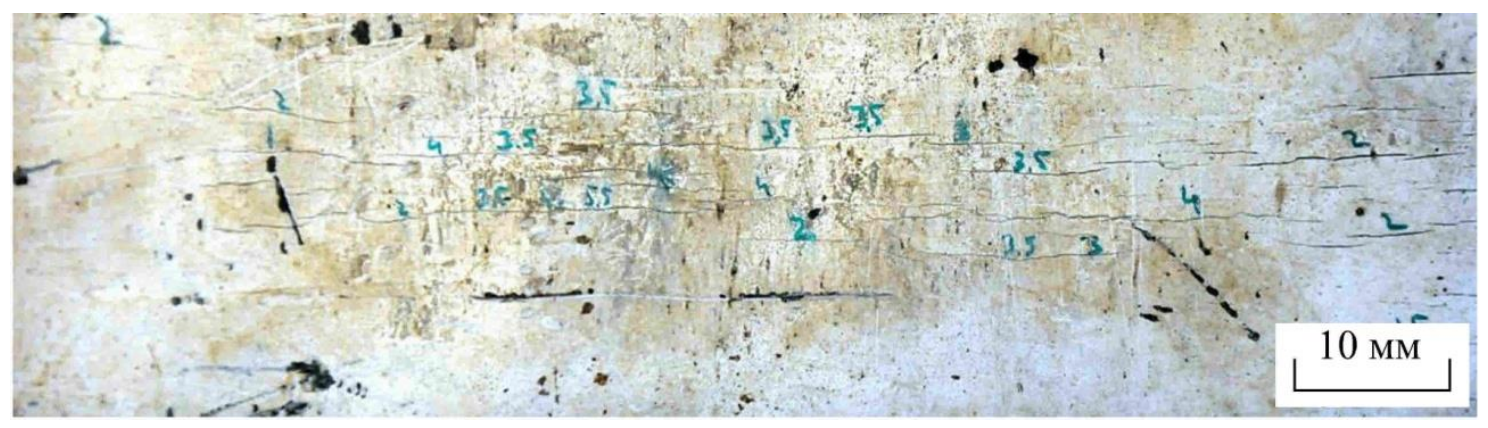

Рис. 2. Трещины, обнаруженные на темплете

Прежде чем рассматривать модель представления взаимодействующих трещин необходимо выбрать представление одной трещины. Единичная трещина (рис. 3) может быть представлена в виде эквивалентной полуэллиптической трещины [1]. В таком случае рост трещины в длину происходит через смещение вершин трещины в противоположном направлении, а рост трещины в глубину можно упрощенно считать равномерным [2].

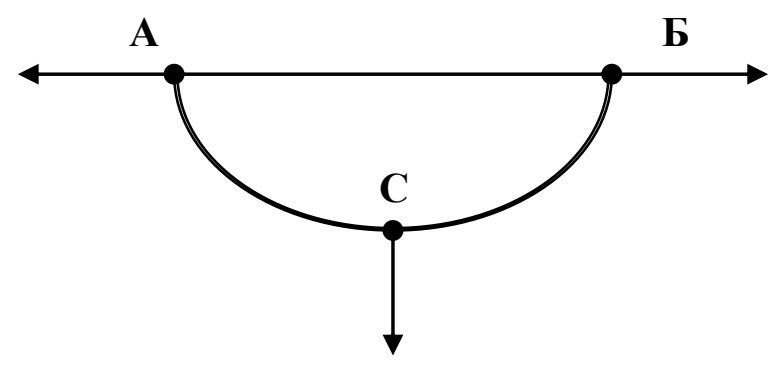

Рис. 3. Модель единичной трещины с двумя вершинами А и Б и точкой максимальной глубины C

\section{3. Результаты и обсуждение}

Анализ расположения отдельных единичных трещин позволяет выявить встречающиеся на данном темплете варианты взаимодействия двух близкорасположенных трещин. Сле- 
дует отметить, что, согласно нормативной документации Газпром, близкорасположенными дефектами будут считаться соседние стресс-коррозионные дефекты, если расстояние между ними не превышает половины длины наибольшего дефекта при его длине меньше пяти толщин стенки трубы, если же его длина больше, то соседним считается дефект на расстоянии меньшем пяти толщин стенки трубы [3].

Большое число трещин позволяет выделить основные способы объединения единичных трещин в один протяженный дефект. В рамках данной работы ледует разделять единый протяженный дефект, (образованный объединением трещин) и одиночный дефект в нормативной документации (представляющий поле трещин). Дальнейшие обсуждения относятся только к первому варианту.

Изначально все трещины имеют параллельную ориентацию, расположенную перпендикулярно максимальным действующим напряжениям в стенке трубы, в данном примере это продольное расположение, которое составляет 95 \% обнаруженных дефектов КРН на газопроводах [4]. По мере удлинения трещины могут изменить направление развития навстречу друг другу (рис. 4). Отмечены варианты, когда трещины, расположенные на одной образующей трубы, объединяются последовательно (рис. 5). При незначительном, порядка нескольких миллиметров, расстоянии в поперечном направлении объединение трещин происходит путем присоединения начала (конца) одного дефекта к середине другого (рис. 6). Однако встречаются варианты, когда трещины развиваются параллельно или даже отклоняются от линии развития друг друга (рис. 7) без видимого взаимодействия.
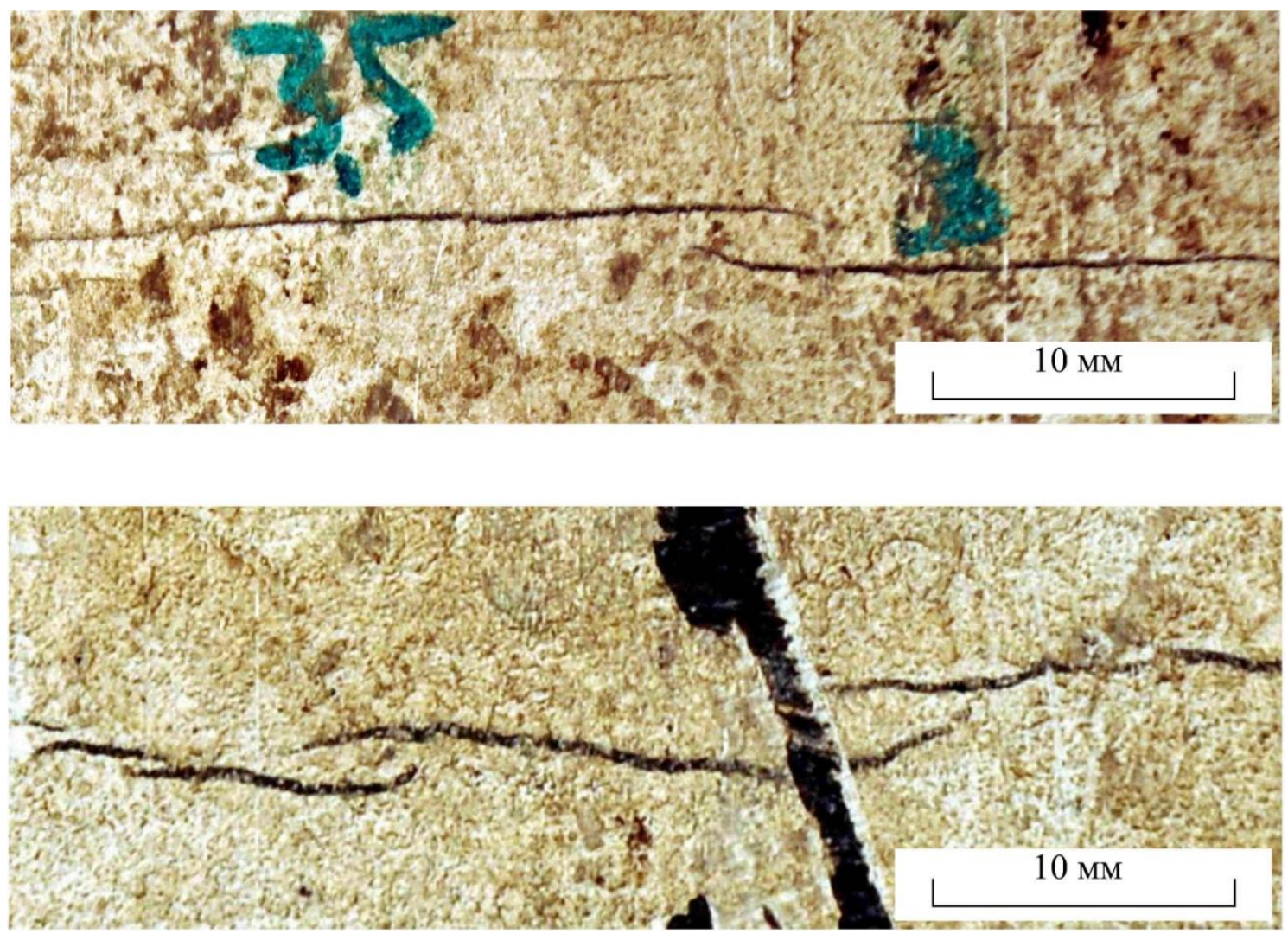

Рис. 4. Напрвление роста трещин, стремящихся к объединению 


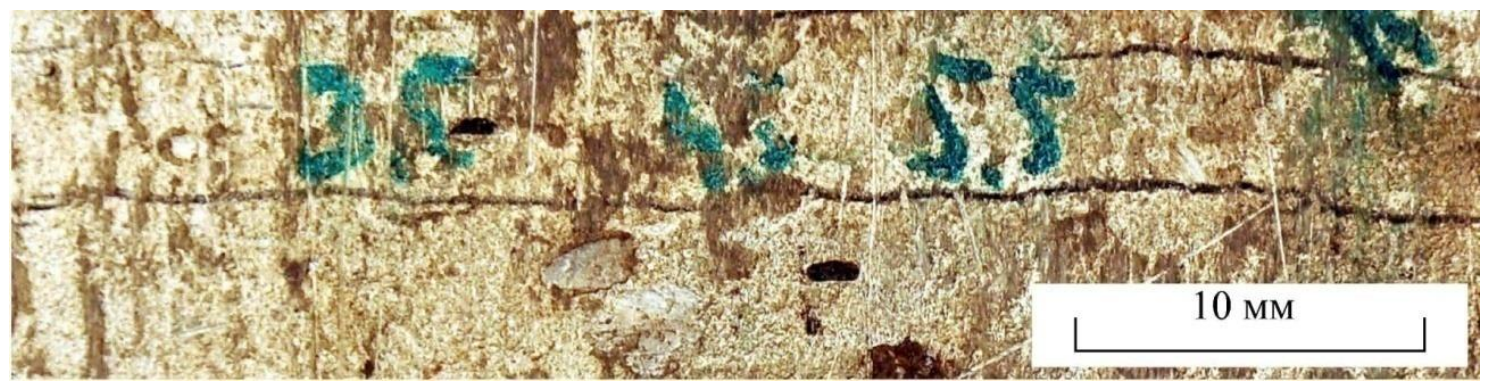

Рис. 5. Последовательное объединение трещин

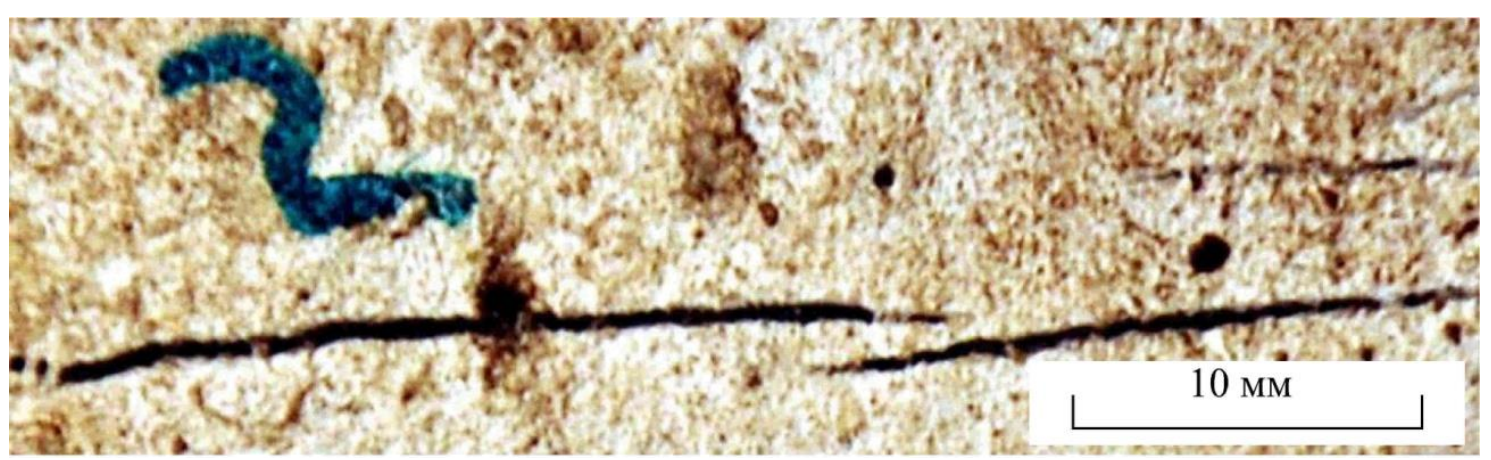

Рис. 6. Присоединение трещины вершиной к средней части соседней трещины
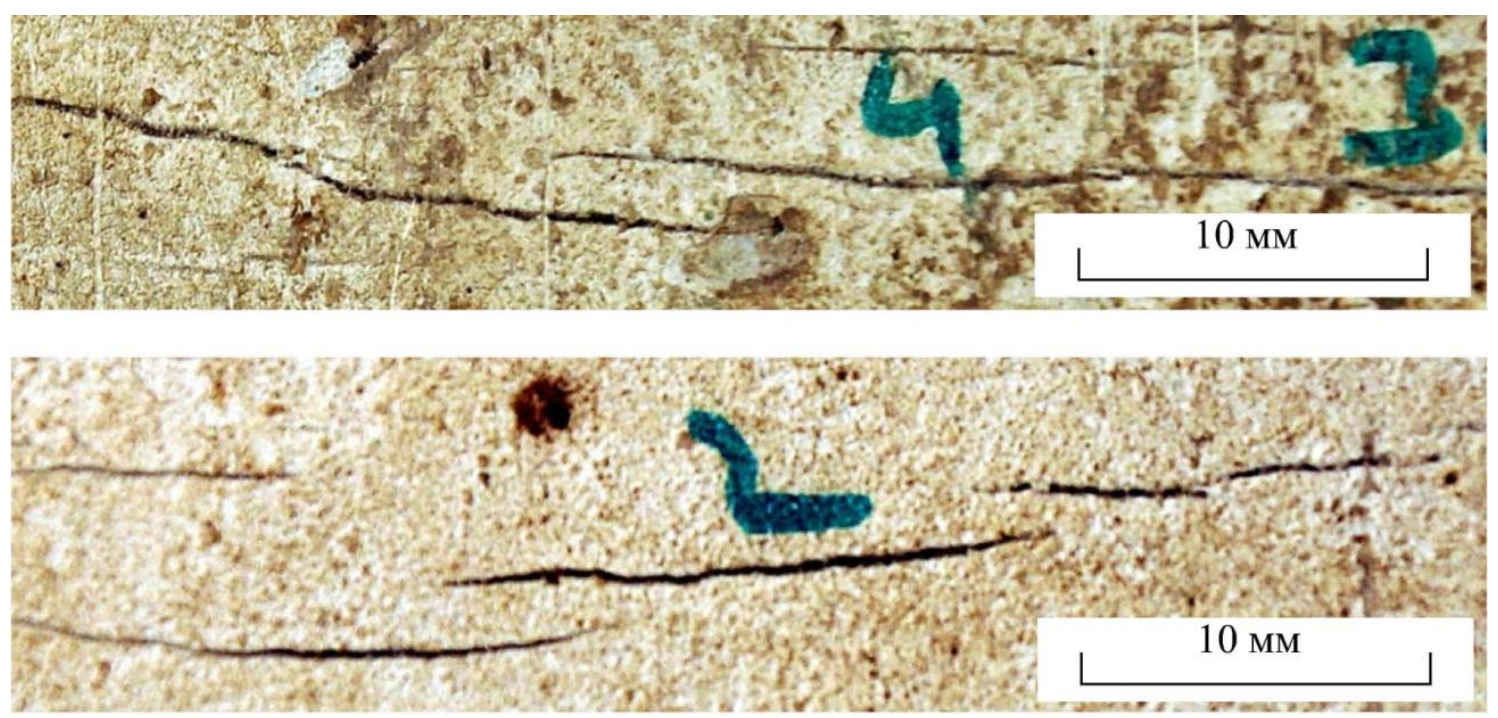

Рис. 7. Параллельное развитие трещин без объединения

Таким образом, по способу объединения двух трещин можно выделить несколько вариантов (рис. 8): две трещины объединяются вершинами (обозначение $\mathrm{A}_{1} \mathrm{~b}_{2}$ или $\mathrm{A}_{2} \mathrm{~b}_{1}$ ); одна трещина присоединяется вершиной к телу другой трещины (обозначение $\mathrm{A}_{1} \mathrm{C}_{2}, \mathrm{~b}_{1} \mathrm{C}_{2}, \mathrm{~A}_{2} \mathrm{C}_{1}$ или $\mathrm{b}_{2} \mathrm{C}_{1}$ ); однако вариант объединения вершинами $\mathrm{A}_{1} \mathrm{~A}_{2}$ или $\mathrm{A}_{1} \mathrm{~A}_{2}$ на темплете не обнаружен. 


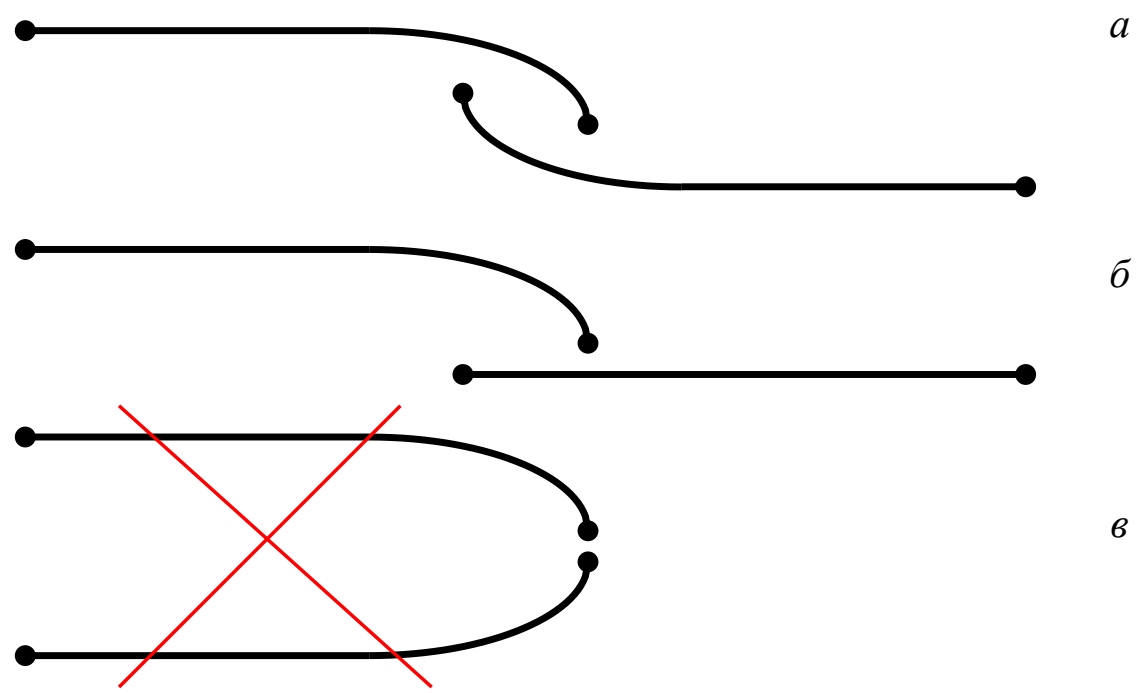

Рис. 8. Варианты объединения двух трещин: противоположными вершинами $(a)$, вершины и тела трещины (б), односторонними вершинами (в) - не обнаружено

Отсутствие взаимодействия между односторонними вершинами трещин и «притяжение» противоположными вершинами позволяет выбрать модель трещины в виде диполя (рис. 9). В этом случае условному заряду в вершинах диполя, от величины которого зависит расстояние, на котором трещины начинают движение к объединению, можно поставить в соответствие коэффициент интенсивности напряжения, который используется в линейной механике разрушения для описания полей напряжений у вершины трещины [5].

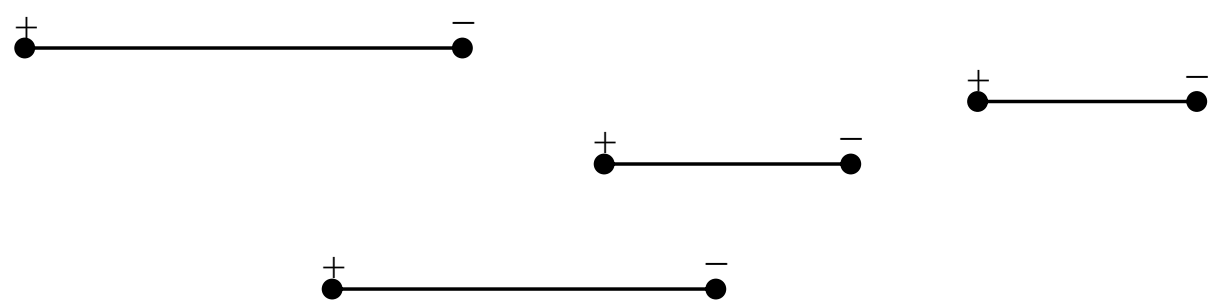

Рис. 9. Поле трещин с использованием дипольной модели

\section{4. Заключение}

Анализ различных случаев объединения трещин коррозионного растрескивания под напряжением на реальном объекте позволяет рассматривать для оценки взаимного влияния только близкорасположенные трещины. Обнаруженная избирательность при слиянии трещин в единый дефект проявляется отсутствием объединения трещин односторонними вершинами. Предложен дипольный вариант модели для построения объединения развивающихся трещин, при котором сила взаимодействия близкорасположенных трещин может быть связана с коэффициентом интенсивности напряжений.

\section{Благодарность}

Работа выполнена в рамках государственного задания ФАНО России (тема «Диагностика», № AAAA-A18-118020690196-3) 


\section{Литература}

1. СТО Газпром 2-2.3-173-2007. Инструкция по комплексному обследованию и диагностике магистральных газопроводов, подверженных коррозионному растрескиванию под напряжением. - М. : Газпром экспо, 2008. - 29 с.

2. Инструкция по оценке дефектов труб и соединительных деталей при ремонте и диагностировании магистральных газопроводов. - М. : ООО «ВНИИГАЗ», 2013. - 117 с.

3. Диагностика коррозионного растрескивания газопроводов.Атлас / С. В. Алимов, И. А. Долгов, В. А. Горчаков, Ю. П. Сурков, А. Ю. Сурков, В. Г. Рыбалко / под ред. Ю. П. Суркова. Екатеринбург : УрО РАН, 2004. - 84 с.

4. СТО Газпром 2-2.3-137-2007. Инструкция по технологиям сварки при строительстве и ремонте промысловых и магистральных газопроводов. Ч. 2. - М. : Газпром, 2007. - 177 с.

5. Броек Д. Основы механики разрушения / пер. с англ. - М. : Высшая школа, 1980. - 367 с. 